\title{
A Case of Congenital Lumbar Hernia
}

Manikyamba $\mathrm{D}^{1}$, Vijayalakshmi $\mathrm{VV}^{2 *}$, Lakshmi Raghavi J ${ }^{3}$

${ }^{1}$ Professor, ${ }^{2}$ Assistant Professor, ${ }^{3}$ Post Graduate, Department of Neonatology, Government general hospital, Rangaraya Medical College, Kakinada

DOI: $10.36347 /$ sjmcr.2020.v08i03.035

| Received: 12.03.2020 | Accepted: 20.03.2020 | Published: 24.03.2020

*Corresponding author: V.V. Vijayalakshmi

\section{Abstract}

Lumbar hernia can be either congenital or acquired. It is a rare entity with common associations like lumbocostovertebral syndrome, anorectal malformations, congenital heart diseases, renal anomalies, etc. We report a case of congenital lumbar hernia with anorectal malformation and vertebral anomalies in a new born female baby.

Keywords: Lumbar, hernia, congenital, anorectal malformation.

Copyright @ 2020: This is an open-access article distributed under the terms of the Creative Commons Attribution license which permits unrestricted use, distribution, and reproduction in any medium for non-commercial use (NonCommercial, or CC-BY-NC) provided the original author and source are credited.

\section{INTRODUCTION}

Lumbar hernia is herniation of intraabdominal contents between the $12^{\text {th }} \mathrm{rib}$ and iliac crest with the aponeurosis of transverse muscle covered by the latissimus dorsi muscle [1]. Congenital lumbar hernia is a rare type of hernia often associated with a multiple of congenital anomalies involving ribs, spine, spinal meninges, muscles and kidneys [2, 3]. As few as 50 cases of lumbar hernia associated with other congenital anomalies have been reported in literature till now [4].

\section{CASE REPORT}

A $2.7 \mathrm{~kg}$ term female baby born out of non consanguineous marriage by vaginal delivery to a shortstatured $2^{\text {nd }}$ gravida mother was admitted in NICU, Government general hospital Kakinada, East Godavari district, Andhra Pradesh, with a complaint of swelling on the left posterolateral part of the abdomen. On examination, a swelling of size $5 \times 4 \mathrm{~cm}$, soft in consistency, with an expansile impulse on crying was present on the left posterolateral part of the abdomen. The baby was further examined to rule out other congenital anomalies. There was anal atresia with recto vestibular fistula. Heart sounds were better heard on the right side of the chest with apex beat palpable in right $4^{\text {th }}$ intercostal space suggestive of dextrocardia. X-ray abdomen showed air -filled bowel loops in the sac on the left side. X-ray spine showed vertebral defects in dorsal region. Lumbar hernia was confirmed with contrast enhanced CT. Butterfly vertebra was noted in D11, hemivertebra in D12 segment and vertebral clefts in the lumbar region. 2D echo was done to confirm dextrocardia. The child underwent a surgical repair that is right transverse colostomy for anorectal malformation. Open repair of lumbar hernia and posterior sagittal anorectoplasty were planned in follow up.

\section{DisCUSSION}

Congenital lumbar hernias are rarely seen and constitute less than one percent of abdominal hernias. They usually present as compressible soft tissue swellings. The lumbar region is divided into two triangles, superior or Grynfelt triangle and inferior or Triangle of Petit. Superior triangle is bounded by $12^{\text {th }}$ rib above, quadratus lumborum muscle medially and by the posterior border of internal oblique muscle laterally. Inferior triangle is bounded below by the crest of ilium, external oblique muscle laterally and by the latissimus dorsi muscle medially [5]. Lumbar hernias most commonly occur through the inferior triangle of Petit [6].
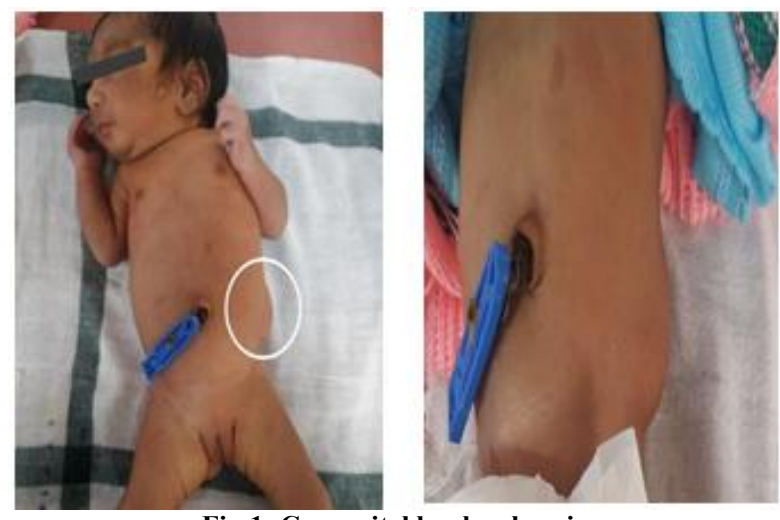

Fig-1: Congenital lumbar hernia 


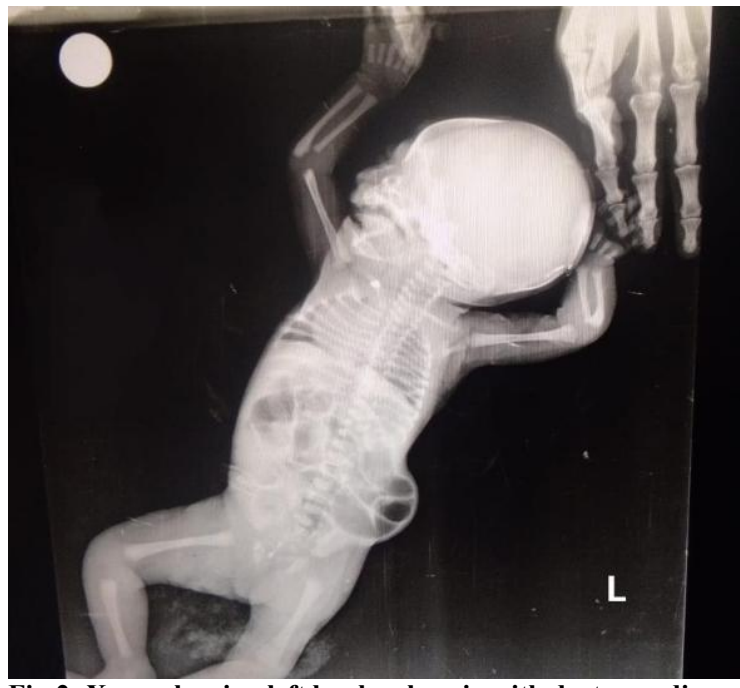

Fig-2: X-ray showing left lumbar hernia with dextrocardia

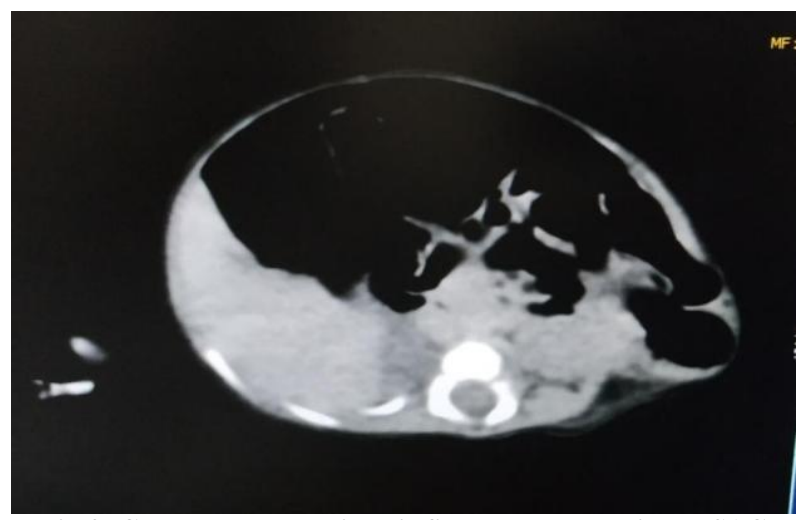

Fig-3: CT abdomen showing air filled bowel loops in the SAC

They could be spontaneous, post- traumatic or post-operative in origin. A single somatic mutation in early embryogenesis probably due to transient anoxia causes derangement of lumbar muscles and aponeurosis leading to herniation causing congenital lumbar hernias [7]. Contents of the hernia sac are usually mesentery, appendix, caecum, omentum, stomach, smalllarge intestine, spleen, ovary or kidney rarely. Thorek classified lumbar hernia based on the contents of the hernia to include the presence or absence of peritoneal sac as extraperitoneal, intraperitoneal and paraperitoneal to determine the ideal operative approach [8].

The most common association is lumbocostovertebral syndrome which comprises hemivertebrae, rib abnormalities (absence, hypoplasia etc.), aplasia or hypoplasia of dorsolumbar muscles, scoliosis. Other associations include anorectal malformations, malrotation of gut, eventration of the diaphragm, absence of kidney and congenital heart diseases. Complications include incarceration and strangulation but are rare due to the broad neck of the sac [9]. Clinical examination, x-ray, and ultrasonography help in the diagnosis of lumbar hernia. An abdominal x-ray can detect air -filled bowel loops. Diagnosis can be confirmed by CT or MRI [10]. Lumbar hernia should be differentiated from other abdominal swellings such as lipomas, soft tissue tumors, renal tumors, fibromas, rhabdomyosarcomas, ...,etc. In our case report, the child had a congenital lumbar hernia, anorectal malformation, hemivertebra, dextrocardia with situs solitus which is a very rare entity.

Surgical repair of hernia should be done within one year of life either by open or laparoscopic approach. Other associated anomalies should be managed appropriately. Regular follow up is essential to check for the complications.

\section{CONCLUSION}

Congenital lumbar hernia with an anorectal malformation, hemivertebra, and dextrocardia is a rare presentation. This is the first case reported from our institution. Early repair and regular follow- ups carry a better prognosis.

\section{REFERENCES}

1. Geis WP, Hodakowski GT: Lumbar hernia. In: Nyhus LM, Cohen RE (eds). Philadelphia, JB Lippincott Co, 4th Ed. 1995, 416-18.

2. Karmani S, Ember T, Davenport R. Congenital lumbar Hernias:A case report. J Pediatr Surg. 2002;37:921 -22.

3. Barrero CR, Garrido MM. Congenital lumbar hernia and bilateral renal agenesis. Cir Pediatr. 2007; 20 (2);133-35.

4. Wakhlu A, Wakhlu AK. Congenital lumbar hernia. Pediatric surgery international. 2000 Jan 1;16(12):146-8.

5. Sarela AI, Mavanur AA, Bhaskar AA, Soonawala ZF, Devnani GG, Shah HK, Samsi AB. Post traumatic lumbar hernia. Journal of postgraduate medicine. 1996 Jul 1;42(3):78.

6. Ranka SR, Bakshi G, Kamal M, Mohite JD. Lumbar Hernia. Bombay Hosp J. 2000; 42: 635-37.

7. Touloukian RJ. The lymbocostovertebral syndrome: a single somatic defect. Surgery. 1972 Feb;71(2):174-81.

8. Thorek M. Modern Surgical Technique Philadelphia: JB Lippincott; 1950: 23-32

9. Swartz WT. Lumbar hernia. In:Nyhus LM,Condon RE(eds).Hernia, 2nd ed. Philadelphia: Lippincott. 1978: 409-26.

10. Faro SH, Racette CD, Lally JF. Traumatic Lumbar Hernia. CT diagnosis. Am J Radiol. 1987;148:56567. 